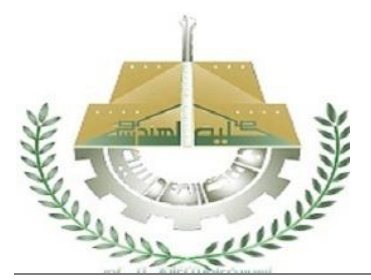

\title{
DAMPING SUB SYNCHRONOUS RESONANCE IN POWER SYSTEM USING TCSC \& SVC
}

\author{
Khalid A. Nabhar \\ Electrical Engineering Department, University of Basra. \\ Email: khalidabd9495@gmail.com \\ Basim T. Kadhem \\ Electrical Engineering Department, University of Basra. \\ Email: basim72_sh@yahoo.com
}

\begin{abstract}
: when the steam turbine-generator is connected with series of compensation along the transmission line, the sub synchronous resonance may happen. The Flexible Ac Transmission System (FACTS) controller of the devices wide use which has been used to reduce and suppress the phenomenon of sub-synchronous resonance the Thyristor Control Series Compensation (TCSC) and Static VAR Compensation (SVC) are the types of FACTS controller that has been used to put down the SSR and also for the purpose of provide a better and efficient solution to improve the transferred capacity system to connect the series compensation along the transmission line. Series capacitor work to increase the chance of creating sub synchronous resonance. Series capacitors also have an inclination to amplify the shaft stress during considerable network transien toccurrence, SSR phenomena happen which can cause damage of the shaft generator turbine. The first standard model of IEEE was adopted to study this phenomenon. This research deals the PID control of SVC( Static VAR Compensation) and TCSC (Thyristor Controlled Series Compensator) and excitation system controller for reducing SSR in power system. In this research, the method of Eigenvalue was used to analysis the sub-synchronous resonance phenomenon and the result was verified using DYMOLA simulation
\end{abstract}

Keywords: Series Capacitive Compensation, Sub Synchronous resonance, TCSC, SVC, Eigen value, FACTS device, Torsional oscillation.

\section{INTRODUCTION}

The power consumption by the utility is subsequently increased continuously. The increase in power demand had compelled the power engineers to use long transmission line which enables bulk power transfer. In order to satisfy the load demand in long transmission lines, series of capacitive compensations are being used which increase the power delivering capability of the transmission line effectively. Further, it also improves the transient stability of the system [1]. Because of series capacitive compensation the problem of sub synchronous resonance may occur in long transmission lines. The SSR problem relates to the torsional interactions between the generator rotor section and turbine section of the plant. The interactions between these two masses are caused due to sub harmonic frequencies produced by the series capacity compensator [2]. This interaction causes shaft failure in the turbo- generator system. This phenomenon was first experienced in the year of 1937 but it got noticed in the 1970s after two turbine-generator shaft failures occurred at the Mojave generating station in Southern Nevada [3]. The SSR problem is further divided into two categories namely, torque amplification (TA) also known as transient torque and steady state SSR. The steady state SSR is further divided to torque interaction (TI) and induction generator effect (IEG) [4]. In this paper TI problem is taken into consideration which bears a threat to power system. A flexible ac transmission system is 


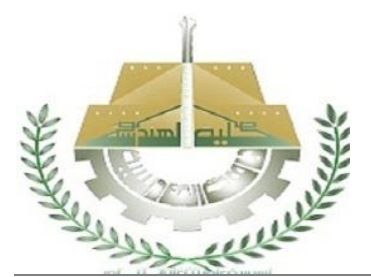

JOURNAL OF AL-QADISIYAH FOR ENGINEERING SCIENCE

used in power system to improve power quality, power security and its integration. The FACTS devices have several uses in the power system but mainly they are used for reactive and real power compensation, to improve power system stability both transient and steady state, to control the line impedance, to suppress the harmonics, to improve the power factor of the system and even to mitigate the SSR problem. To suppress the sub harmonic oscillations there are many FACTS devices like static synchronous compensator (STATCOM), Static Voltage Compensator (SVC), Static Series Synchronous Compensator (SSSC), Unified Power Flow Controller (UPFC) and Thyristor Controlled Series Compensator (TCSC) that can be used in the system. This paper uses TCSC and SVC as FACTS devices for eliminating the SSR problem from the system due to the several advantages of this type over other FACTS devices. Have been used for reducing torsional oscillation in series capacitive compensating system for the analyzing of SSR, IEEE First Benchmark Model (FBM) the simulation results of these devices are obtained from dymola software by considering two systems first without FACTS devices and second with FACTS appliances. These results are then compared to know the effectiveness of TCSC \& SVC on reducing of SSR oscillations. Shashidhara Mecha Kotian, [5]. In this research, a dynamic phasor-based continuoustime model of TCSC has been used to result the phaseresponse characteristies of a system analysis. This conversely can, the used of the known the mechanism phase compensation to designing a additional sub-synchronous damping control. It is found that at higher series compensation levels, the designing relys on the change in the fring angle of the thyristor control series compensation TCSC is an important type of type which is increasingly used in long transmission lines in modern power system. $R$. Zheng,[6]. In this research, the sub-synchronous resonance phenomenon is suppressed by using modern control to control the TCSC. various from traditional sub-synchronous damped control, this planner include used solitary local measure that may be effective acquired at the thyristor control series compensation direction. TCSC is a type of series appliance which allows moving fast also uninterrupted transmission line variable impedance [7]. can be classified the TCSC as an appliance series compensation, be possible numerous profits for a power system as well as a control process, flow power during transmission line reducing oscillation mode, as well as put out the status and resonance that appear [8]. For this purpose, the IEEE benchmark first model, in Fig.1, that is submitted for studying SSR phenomenon in three cases has been used:

1. WITHOUT ANY COMPENSATION .

2. COMPENSATION BY TCSC.

3. COMPENSATION BY TCSC \&SVC.

WITH ONE SYMMETRICAL THREE PHASE SHORT CIRCUIT

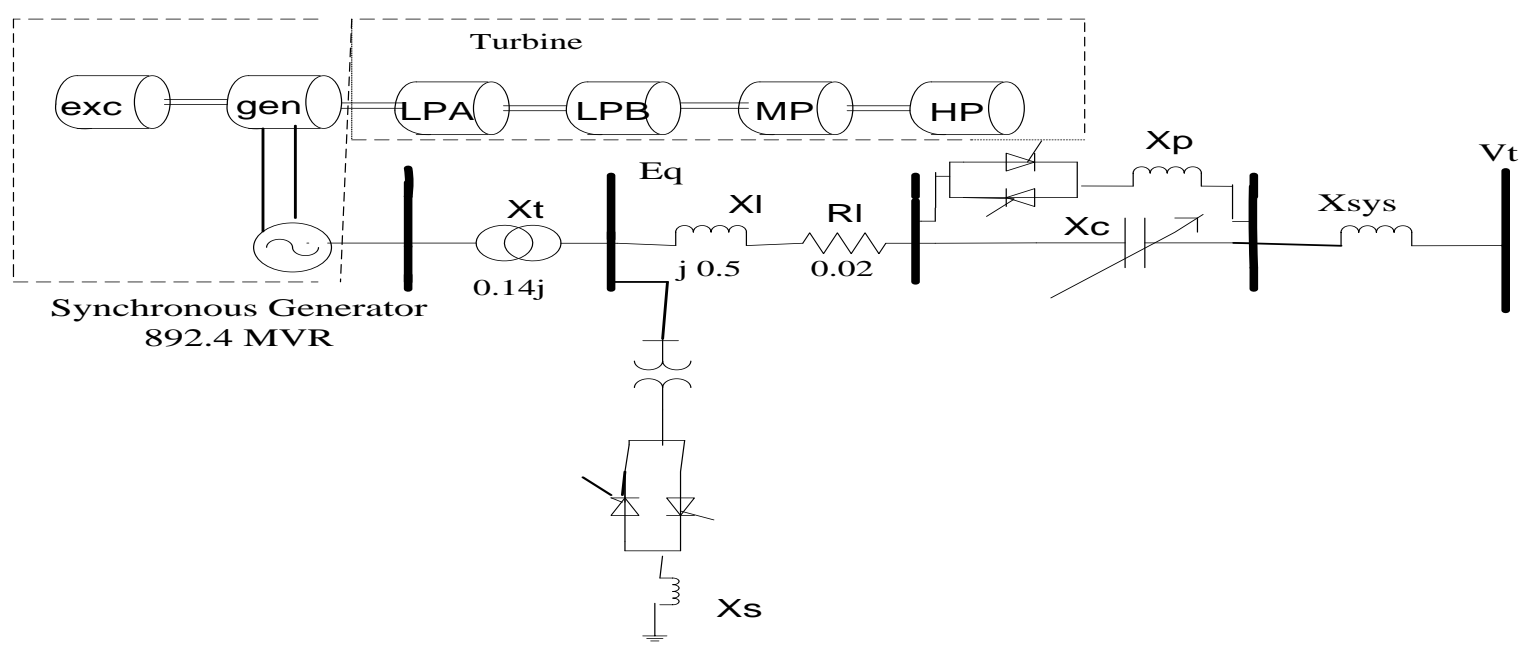

Figure.1.IEEE first benchmark model 


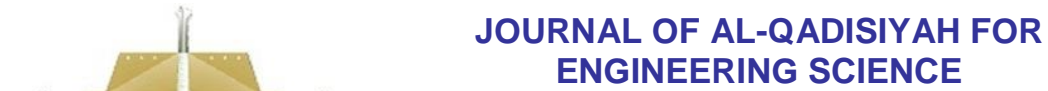

ENGINEERING SCIENCE
Vol. 11 , No. 2

ISSN: $1998-4456$

\section{SYSTEM MODEL}

\subsection{Power System}

The study system is the IEEE benchmark first modeling [10]. For SSR analysis, described in Fig.1.(892.4 MVA/ 500 $\mathrm{KV} / 50 \mathrm{HZ} / 3600 \mathrm{rpm}$ ) connect the synchronous generator into the infinite bus passing through transmission line with TCSC \&SVC with capacitor is constant or whose inductance is different through the control values angle thyristor can be control in its value terminal voltage. Shaft consists of several pieces, including one piece for high pressure and one for medium pressure and two pieces of low pressure and generator and exciter system. The shift frequency system has five torsional modes at $98 \mathrm{rad} / \mathrm{sec}, 127 \mathrm{rad} / \mathrm{sec} 161 \mathrm{rad} / \mathrm{sec}, 203 \mathrm{rad} / \mathrm{sec}, 298 \mathrm{rad} / \mathrm{sec}$. The machine using in the study consists of two damper winding in quadratic axis while have one damper winding in direct axis, one winding afield were considered. The electrical and mechanical systems were modeled using the Dymola program. The complete electrical and mechanical data for the studied system are presented in reference [11].

\subsection{Excitation System}

The main aim of the excitation system is to equip the direct current to the synchronous generator windings. It consists of a system of excitation protection units as well as an automatic regulator of voltages and exciter [12]. An integrated control loop can be inserted as well as a power system stabilizer capability that provides additional signal for the control loop to eliminate sudden disturbances that may adversely affect the process of damping [13]. The excitation considered her is IEEE STA1 as seen in Fig.2. The Automatic Voltage Regulator (AVR) used is the so called strong action automatic excitation regulator shown in Fig.3. The purpose of this work is design PID control to a system of excitement to give enhancement to the static and dynamic stability of the power system.

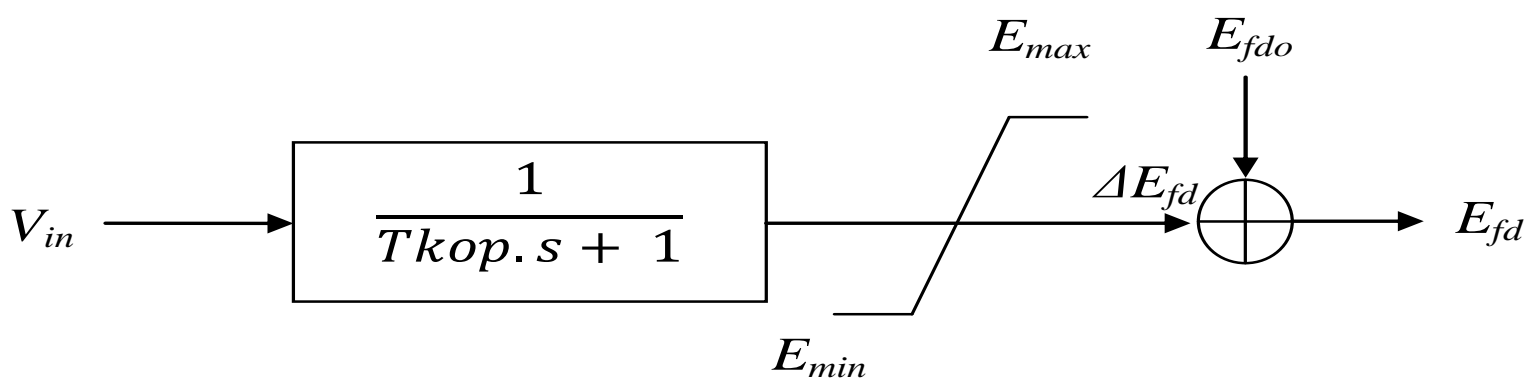

Figure (2) excitation system modeling [14] 

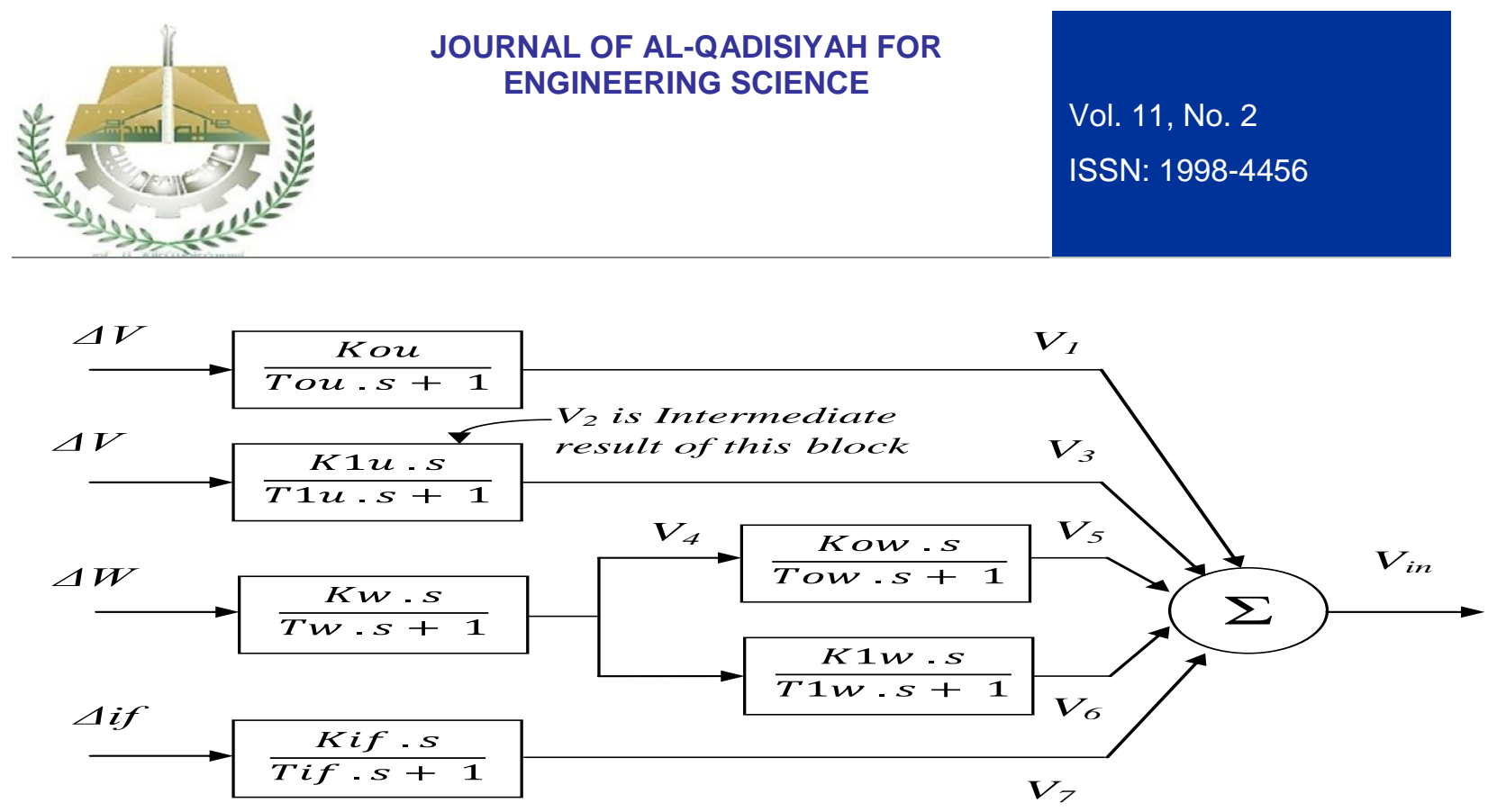

Figure (3) excitation system modeling [14]

\subsection{Static VAR Compensator (SVC)}

The dynamic filter which uses thyristor to modulate the current by way of a shunt connection reactor be possible using to retaliation the SSR problem. The capacitive reactance portion is virtual to be confirmed and reactance portion is taken as changing one by making used of the thyristor switching. The reactor can always be symbolized as controlled voltage source conduct a constant reactor [15]. SVC is used to regulate the reactive power and get a better stability for the system voltage the $\Delta U p$ is a signal auxiliary stabilizing and is added to the input current of the SVC controlled $\Delta \mathrm{Ia}$ to reducing the torsional mode and inertial. Can be used the (TCR) a thyristor controlled reactor as the model of SVC in the study. Fig.4. Exhibits the mathematical model used to control of SVC. 

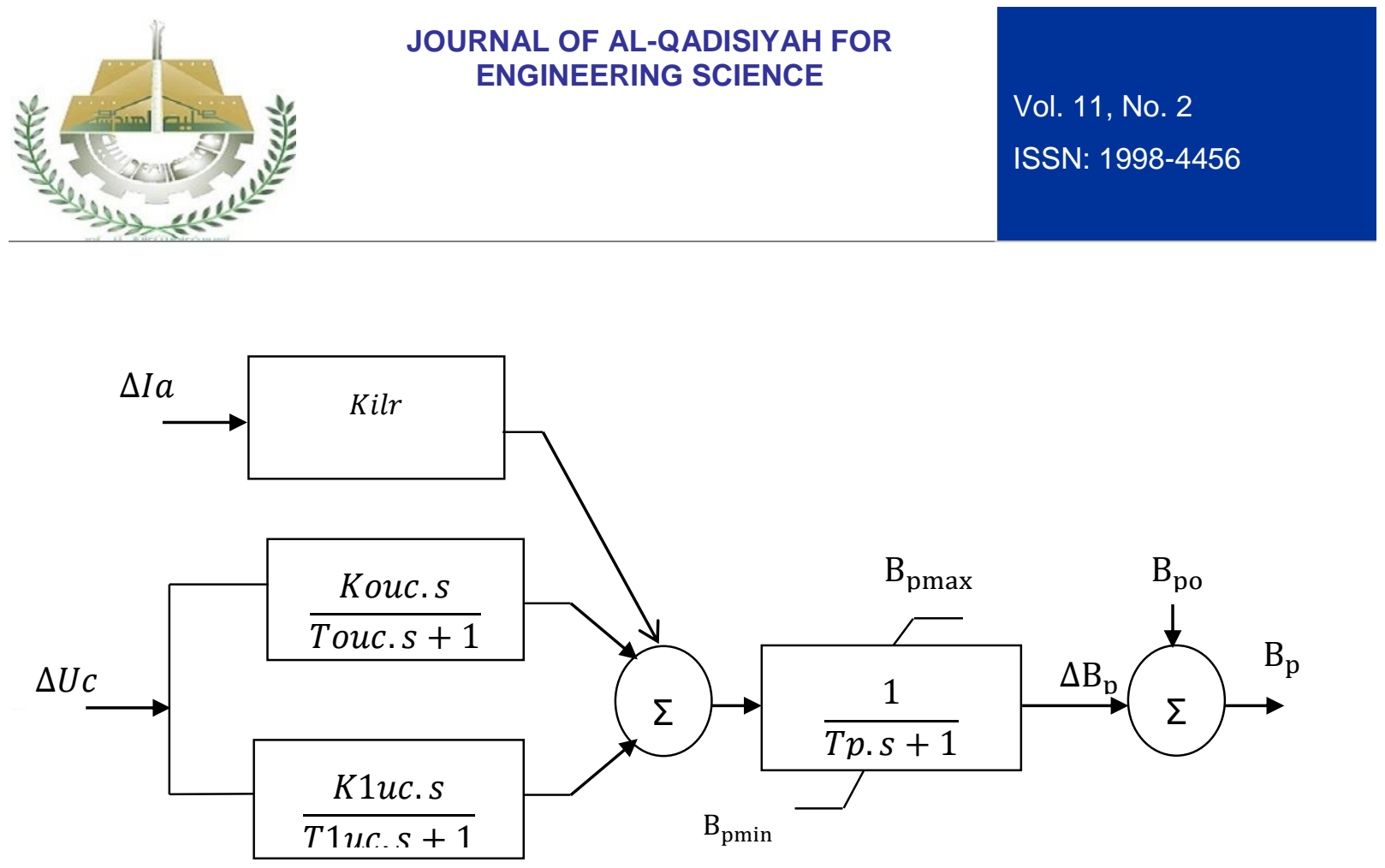

Figure (4) Modeling of static var compensation[17]

\subsection{Thyristor Controlled Series Compensation (TCSC)}

by observing Fig.1.Find that TCSC is composed of a capacitor that is in a parallel state with an inductor join to the thyristor in a corresponding way through the change in the firing angle of the thyristor. Note the change in the inductor value conclude from this case that the TCSC can be considered as variable impedance power system perform TCSC can be used for improvements, namely, enhancing system stability, damping of power oscillations compensating transmission line reactor increasing or controlling power transfer. Due to its flexible control, it becomes an effective device for damping the electromechanical and sub synchronous oscillations. TCSC can operate in capacitive or inductive mode. To change the operating mode of TCSC, firing angle of thyristor is controlled. Although capacitive mode can be consider to be main control mode [16]. The equivalents modeling of TCSC are represented in Fig.5. The terminal voltage input into TCSC across fixed capacitor error $\Delta U_{c}$ the signal auxiliary $\Delta W_{C}$ is add to $\Delta U_{c}$ to reduce the inertial and torsion oscillation modes. 


\section{SSR ANALYSIS}

The process of exchange between electrical and mechanical systems is called the SSR phenomenon. To analyze this phenomenon we need to represent the electromechanical systems of the generator units and the electronic dynamics of the electromagnetic transport network. In this research we will use the method of eigenvalue for study the SSR in equation 1 description of some electrical and mechanical quantities

$$
M i \delta^{\prime \prime} i+\operatorname{dii} \delta^{\prime} i+\sum_{j=i-1}^{i+1}\left[\operatorname{dij}\left(\delta^{\prime} i-\delta^{\prime} j\right)+\operatorname{kij}(\delta i-\delta j)\right]=\text { Tmi }- \text { Tei } \quad----
$$

for $\mathrm{N}$-mass system it can be written as:

$[M] \delta^{\prime \prime} \mathrm{i}+[D] \delta^{\prime} i+[K] \delta \mathrm{i}=[\mathrm{Tmi}]-[\mathrm{Tei}]=[T]$

where $[\mathrm{M}]$ is a diagonal matrix, consisting of inertia of all masses, $[\mathrm{D}]$ and $[\mathrm{K}]$ are tri-diagonal symmetric matrix consisting of damping coefficient and spring coefficient of the various mass sections. [Tm] and [Te] are the $\mathrm{N}$-vectors of mechanical and electrical torques. [Te] has only one non zero element corresponding to generator rotor. Now if

$$
\begin{aligned}
X & =\left[\delta 1 \delta 2 \delta 3 \delta 4 \delta 5 \delta^{\prime} 1 \delta^{\prime} 2 \delta^{\prime} 3 \delta^{\prime} 4 \delta^{\prime} 5\right]^{\mathrm{t}} \\
X^{\prime} & =\left[\left[\delta^{\prime} 1 \delta^{\prime} 2 \delta^{\prime} 3 \delta^{\prime} 4 \delta^{\prime} 5 \delta^{\prime \prime} 1 \delta^{\prime \prime} 2 \delta^{\prime \prime} 3 \delta^{\prime \prime} 4 \delta^{\prime \prime} 5\right]^{\mathrm{t}}\right.
\end{aligned}
$$

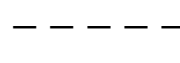

eq. (4) can be written as:

$\delta^{\prime \prime} i=-[M]^{-1}[D] \delta^{\prime} i-[M]^{-1}[K] \delta i+[M]^{-1}[$ Tmi $-T e i]$<smiles>C[AsH3]</smiles>

$\therefore \delta^{\prime} i=[M D] \delta^{\prime} i-[M K]^{-1} \delta i+[M]^{-1}[T m i-T e i]---(6)$

$X^{\prime}=\left[\begin{array}{c}\delta^{\prime} i \\ \delta^{\prime \prime} i\end{array}\right]=\left[\begin{array}{c}0 \\ M K\end{array}\right.$

$\stackrel{I}{M D}] x+\left[\begin{array}{c}0 \\ M^{-1}\end{array}\right] T m i-T e i$

$\therefore \frac{d x}{d t}=[A] x+[B] u$

The eigenvalues or the natural torsional modes of the shaft system are calculated from [A]matrix of the state variable model. The SSR analysis is carried out based on the following initial operating conditions and assumptions:

1. The transportation system receives a sum of $1 \mathrm{pu}$ from the generator.

2. The turbine energy inside it is assumed fixed. 


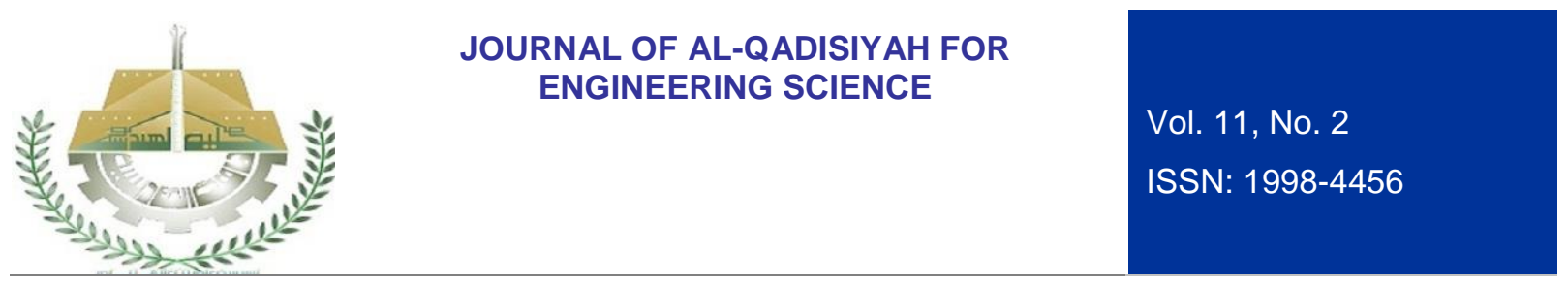

\subsection{Analysis of SSR without Any Damping}

In the first study, by changing the level compensation from ( $0 \%$ to $100 \%)$ we observe that the first IEEE standard system will have four unstable frequencies. This unstable frequencies increase the phenomenon of sub synchronous resonance [18].Without the control of TCSC and SVC, the real part of the eigenvalues corresponding to the various torsional frequencies vary in magnitude and become instability at various levels of series compensation Note that there are different levels of compensation series so the torsional frequencies are different in terms of instability and magnitude as shown in Fig.6. The Table (1) shows the value of real part for each frequency without any damping and using Eigen value analysis.

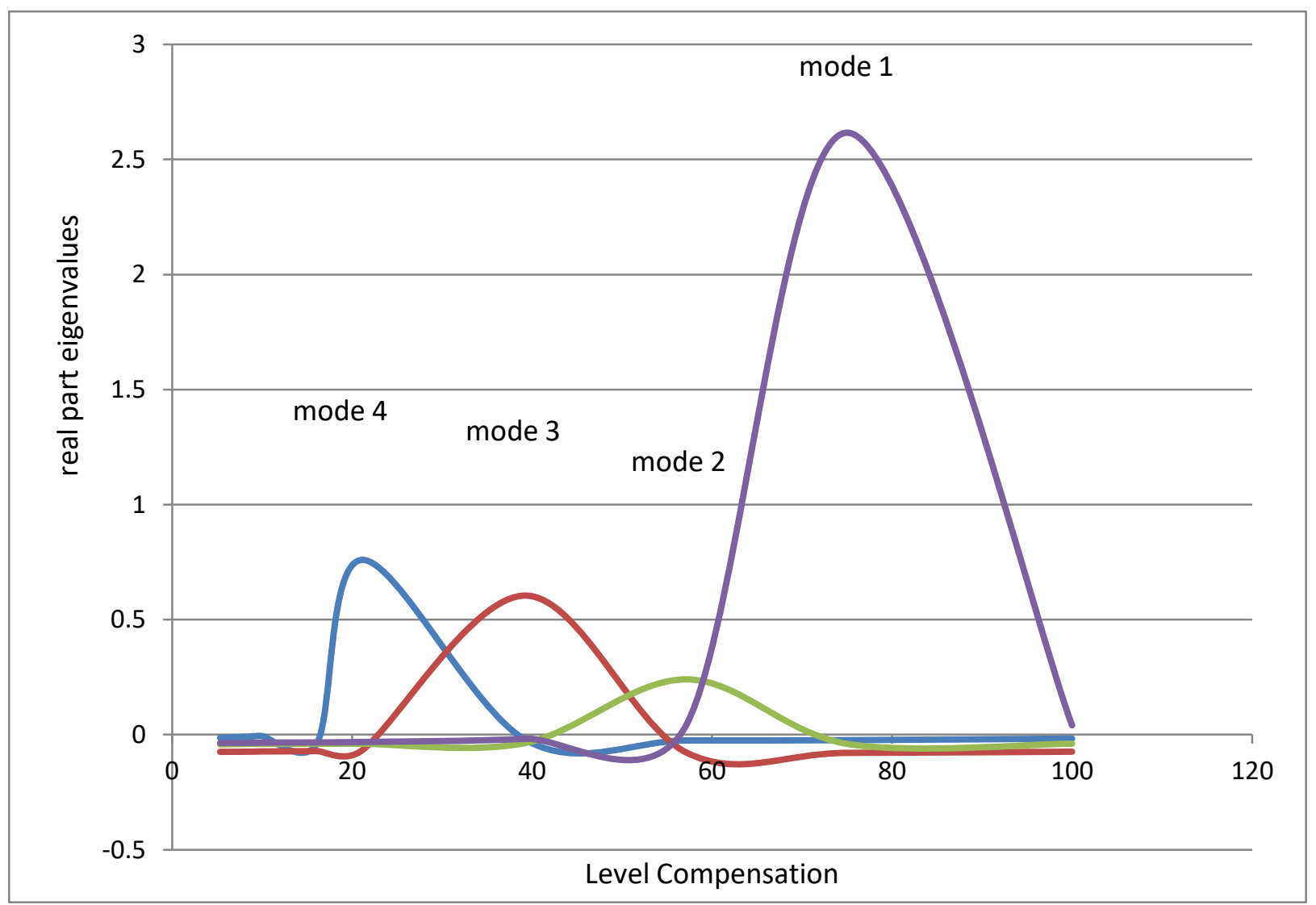

Figure(6).SSR of first benchmark model with level compensation 
Table (1) First benchmark eigenvalues

\begin{tabular}{|c|c|c|c|c|}
\hline \multirow[t]{2}{*}{ Mode } & \multicolumn{4}{|c|}{ \%Compensation Level } \\
\hline & $21.248 \%$ & $39.38 \%$ & $57.14 \%$ & $75 \%$ \\
\hline 0 & $-0.242 \pm 7.7 i$ & $-0.18 \pm 8.6 i$ & $-0.22 \pm 9.28 \mathrm{i}$ & $-0.29 \pm 10.14 \mathrm{i}$ \\
\hline 1 & $-0.032 \pm 98 \mathrm{i}$ & $-0.0184 \pm 98 \mathrm{i}$ & $0.0416 \pm 98 \mathrm{i}$ & $2.617 \pm 98 \mathrm{i}$ \\
\hline 2 & $-0.0396 \pm 127 i$ & $-0.036 \pm 127 \mathrm{i}$ & $0.2402 \pm 127 \mathrm{i}$ & $-0.0398 \pm 127 \mathrm{i}$ \\
\hline 3 & $-0.0676 \pm 161 i$ & $0.6062 \pm 161 \mathrm{i}$ & $-0.0777 \pm 161 i$ & $-0.0793 \pm 161 i$ \\
\hline 4 & $0.7608 \pm 203 i$ & $-0.0227 \pm 203 \mathrm{i}$ & $-0.0253 \pm 203 \mathrm{i}$ & $-0.0238 \pm 203 \mathrm{i}$ \\
\hline 5 & $-0.1002 \pm 299 i$ & $-0.1002 \pm 299 \mathrm{i}$ & $-0.1002 \pm 299 \mathrm{i}$ & $-0.1002 \pm 299 \mathrm{i}$ \\
\hline Elect.mode & $-4.63 \pm 203 \mathrm{i}$ & $-4.28 \pm 161 \mathrm{i}$ & $-3.52 \pm 127 i$ & $-5.212 \pm 98 \mathrm{i}$ \\
\hline
\end{tabular}

\subsection{Analysis of SSR with Control TCSC}

Fig.5. Illustrates the mathmatical model of the TCSC. TCSC can be controlling by using a pro- portional- integralderivative (PID) controller. Many theoretical analysis \& field tests of [19], The torsional oscillations are triggered by the use of a rotor signal to create a shooting angle. The modulation firing angle has few effects on SSR. In TCSC use it to indicate the voltage of the line as well as the speed signal of the generator as a feedback for controling the Eigenvalue, Table (2) shows the values of the torsional mode and the critical levels when controlling the use of the voltage signal as well as the speed indication to control the parameters of TCSC.

Table (2) First benchmark eigenvalues with TCSC control

\begin{tabular}{|c|c|c|c|c|}
\hline \multirow{2}{*}{ Mode } & \multicolumn{4}{|c|}{$\%$ Compensation Level } \\
\cline { 2 - 5 } & $21.248 \%$ & $39.38 \%$ & $57.14 \%$ & $75 \%$ \\
\hline 0 & $-0.821 \pm 6.52 \mathrm{i}$ & $-0.928 \pm 7.22 \mathrm{i}$ & $-1.08 \pm 8.57 \mathrm{i}$ & $-1.24 \pm 9.16 \mathrm{i}$ \\
\hline 1 & $-0.0751 \pm 98 \mathrm{i}$ & $-0.08608 \pm 98 \mathrm{i}$ & $-0.0986 \pm 98 \mathrm{i}$ & $-0.0611 \pm 98 \mathrm{i}$ \\
\hline 2 & $-0.059 \pm 127 \mathrm{i}$ & $-0.0578 \pm 127 \mathrm{i}$ & $-0.04018 \pm 127 \mathrm{i}$ & $-0.053 \pm 127 \mathrm{i}$ \\
\hline 3 & $-0.0936 \pm 161 \mathrm{i}$ & $-0.0876 \pm 161$ & $-0.069 \pm 161 \mathrm{i}$ & $-0.083 \pm 161 \mathrm{i}$ \\
\hline 4 & $-0.058 \pm 203 \mathrm{i}$ & $-0.0085 \pm 203 \mathrm{i}$ & $-0.024 \pm 203 \mathrm{i}$ & $-0.0276 \pm 203 \mathrm{i}$ \\
\hline 5 & $-0.1002 \pm 299$ & $-0.1002 \pm 299 \mathrm{i}$ & $-0.1002 \pm 299 \mathrm{i}$ & $-0.1002 \pm 299 \mathrm{i}$ \\
\hline Elect.mode & $-0.456 \pm 218 \mathrm{i}$ & $-1.49 \pm 174 \mathrm{i}$ & $-1.64 \pm 138 \mathrm{i}$ & $-1.58 \pm 113 \mathrm{i}$ \\
\hline
\end{tabular}




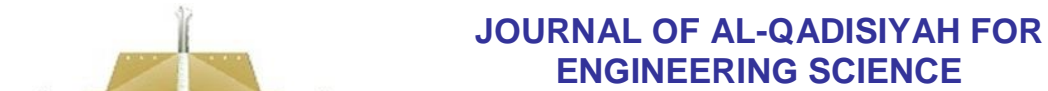

ENGINEERING SCIENCE
Vol. 11 , No. 2

ISSN: $1998-4456$

\subsection{Analysis of SSR with TCSC Control \& SVC}

Fig.1. Illustrate the TCSC\& SVC users for the purpose of study. Using the PID control of TCSC\& SVC in order to minimize the occurrence this case and simple stabilizing signals in case controller of SVC can be used the signals of current and voltage of the generator. These signals provide additional damping at sub synchronous network frequencies. In case the control of TCSC can be use the voltage signal of the line as well as speed signal of the generator as a feedback for control. The Table (3) shows the eigenvalues of the torsional mode and the critical levels when controlling the use of the voltage signal as well as the speed indication to control the parameters of TCSC\&SVC.

Table (3) First benchmark eigenvalues with TCSC control TCSC and SVC control

\begin{tabular}{|c|c|c|c|c|}
\hline \multirow[t]{2}{*}{ Mode } & \multicolumn{4}{|c|}{ \%Compensation Level } \\
\hline & $21.282 \%$ & $39.38 \%$ & $57.14 \%$ & $75 \%$ \\
\hline 0 & $-0.45 \pm 7.27 \mathrm{i}$ & $-0.45 \pm 7.85 \mathrm{i}$ & $-0.5018 \pm 8.57 \mathrm{i}$ & $-0.656 \pm 9.016 \mathrm{i}$ \\
\hline 1 & $-0.0452 \pm 98 \mathrm{i}$ & $-0.04737 \pm 98 \mathrm{i}$ & $-0.04156 \pm 98 \mathrm{i}$ & $-0.0116 \pm 98 \mathrm{i}$ \\
\hline 2 & $-0.0865 \pm 127 i$ & $-0.0845 \pm 127 i$ & $-0.0774 \pm 127 i$ & $-0.0965 \pm 127 i$ \\
\hline 3 & $-0.1045 \pm 161 i$ & $-0.102 \pm 161$ & $-0.097 \pm 161 \mathrm{i}$ & $-0.1038 \pm 161 \mathrm{i}$ \\
\hline 4 & $-0.0756 \pm 203 i$ & $-0.038 \pm 203 \mathrm{i}$ & $-0.0466 \pm 203 i$ & $-0.0501 \pm 203 \mathrm{i}$ \\
\hline 5 & $-0.1002 \pm 299$ & $-0.1002 \pm 299 i$ & $-0.1002 \pm 299 \mathrm{i}$ & $-0.1002 \pm 299 \mathrm{i}$ \\
\hline Elect.mode & $-0.666 \pm 221 \mathrm{i}$ & $-1.001 \pm 177 \mathrm{i}$ & $-0.54 \pm 142 \mathrm{i}$ & $-0.017 \pm 118 \mathrm{i}$ \\
\hline
\end{tabular}

\section{Dynamic Result}

A three phase fault on the machine terminal of duration $(0.01 \mathrm{sec})$ and level compensation $21.248 \%$ will be considered here and the response of the integrated power system to this type of disturbance will be studied. 


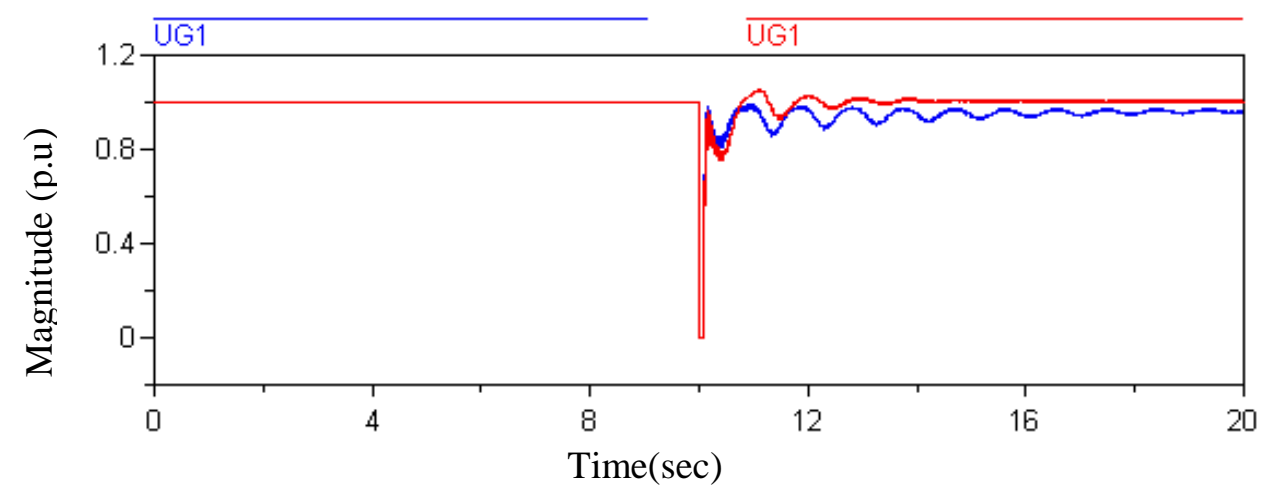

Figure(7) generator terminal voltage

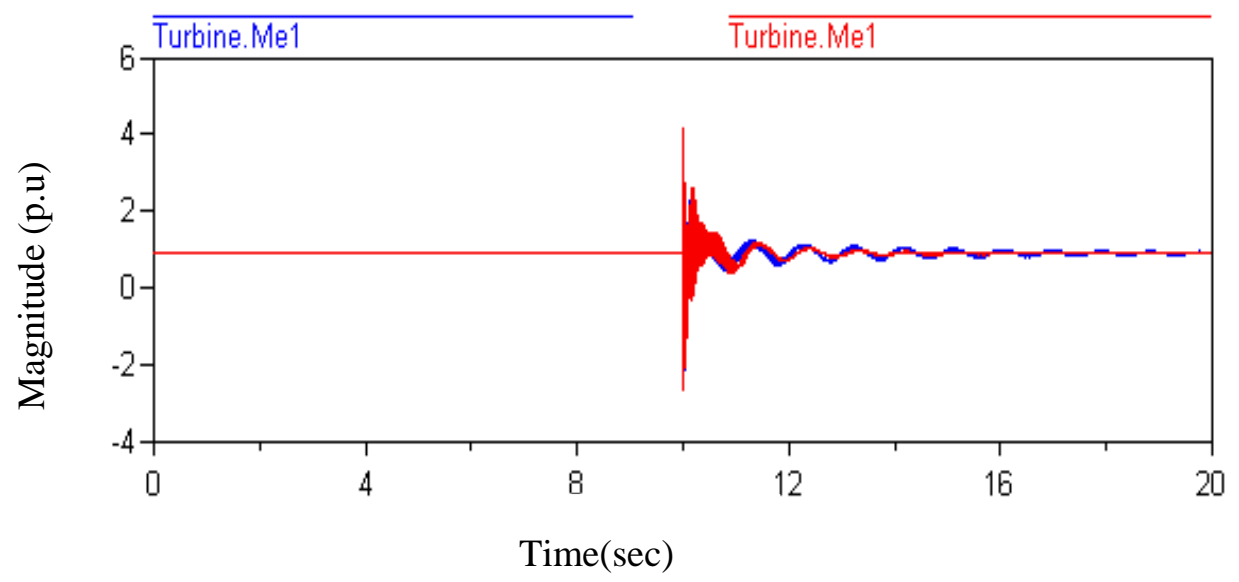

Figure(8) electromagnet torque 

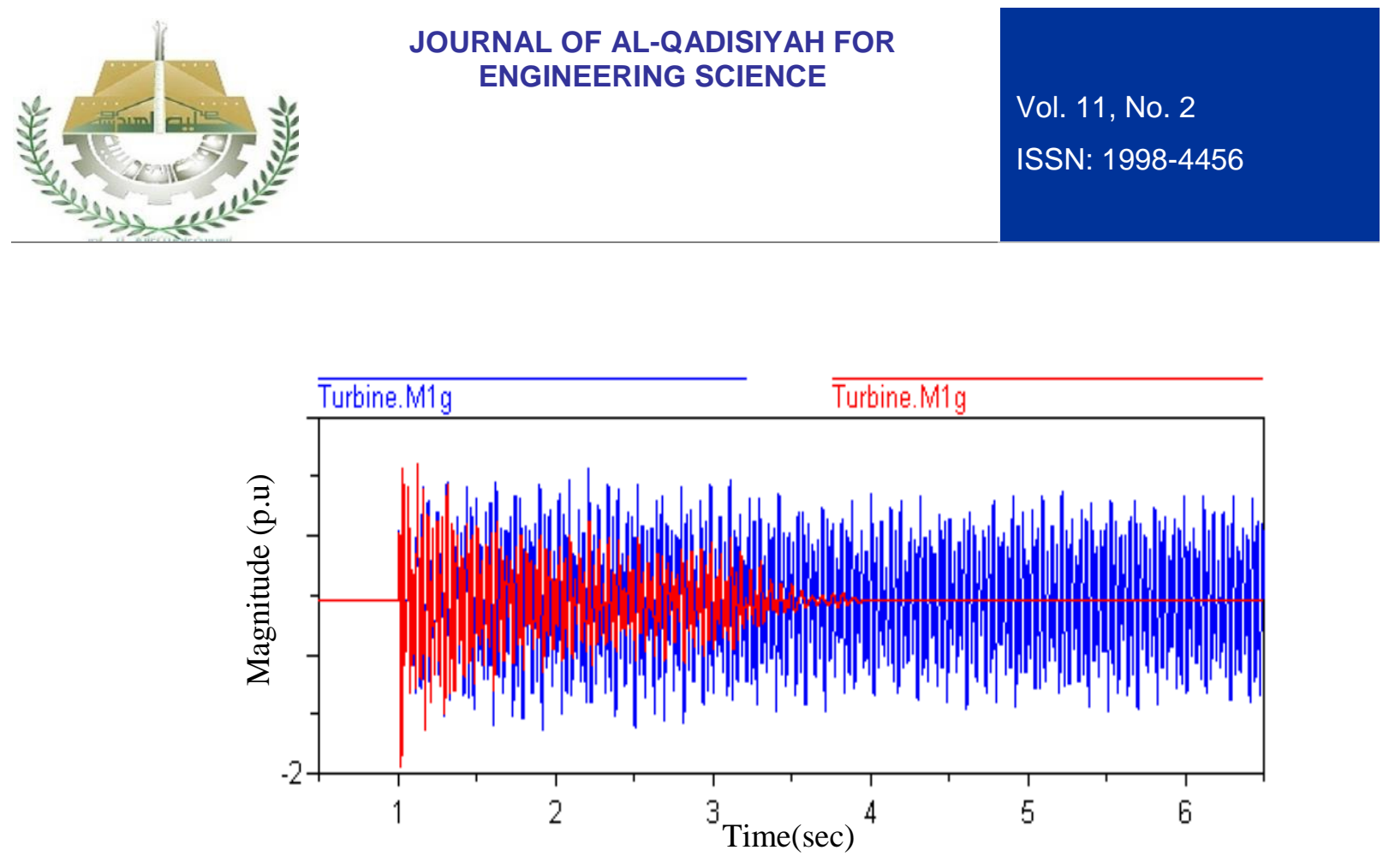

Figure(9) torque between generatar and low presure

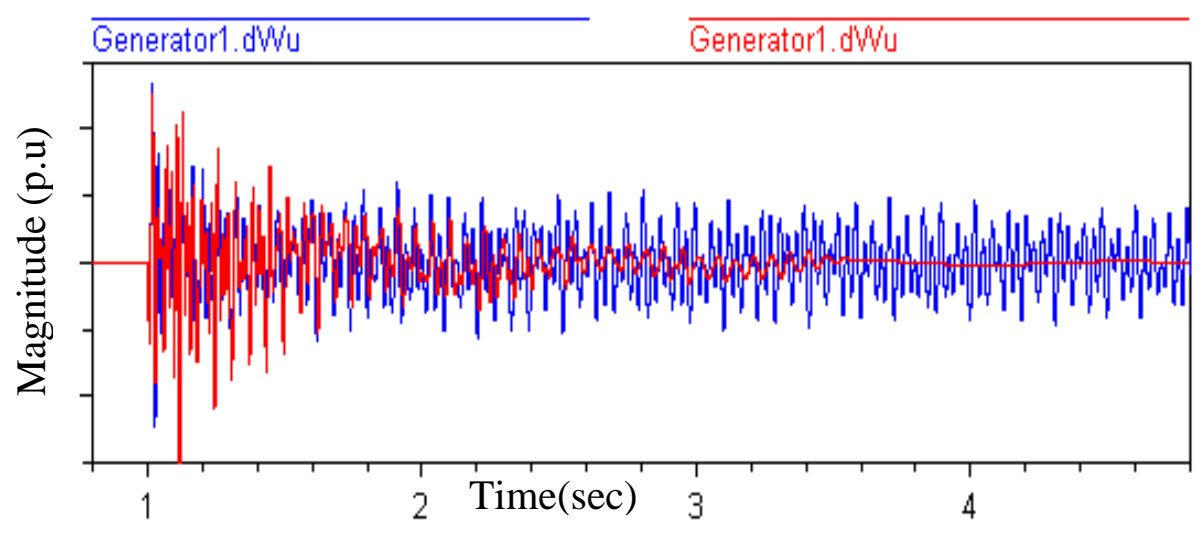

Figure(10) generator speed

In the above figures (from (7) to (10)) the red line represents the signal after gain calculation and the blue line represent the signal with all gains set to zero (without any control).In Fig.7. It can be noted the difference between the voltages signals the red line and the blue line. Fig.8. shows the electromagnet torque of the generator which shows the enhancement of stability when the AVR and TCSC, SVC taken in account. And also note when the occurrence of sub synchronous resonance will cause the non-stability of the system so the use of different control methods for the purpose of obtaining a stable system and the suppression of fluctuations in the system by the use of three types of controllers they are Automatic Voltage Regulation, Static Var Compensation and Thyristor Control Series Compensation (TCSC).So after the occurrence of the three phases fault a certain period of time, the system will return the state of stability due to the presence of control. 


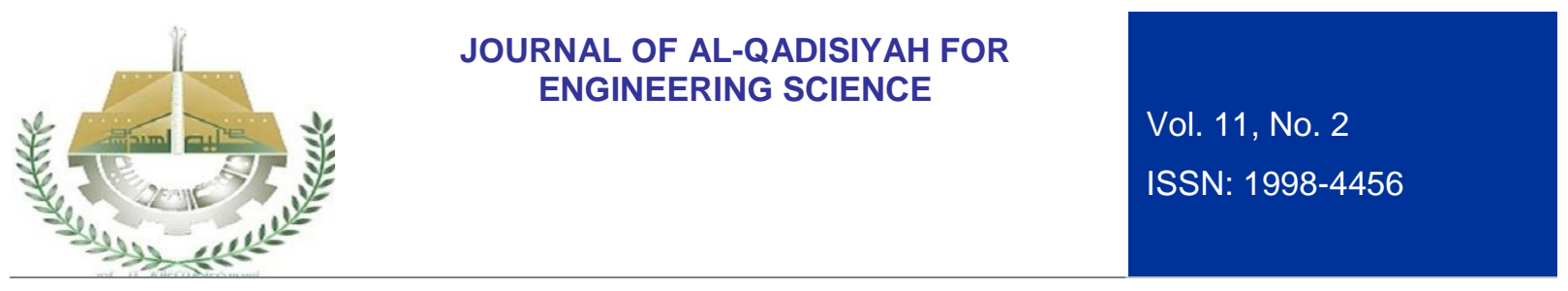

\section{CONCLUSION}

In this paper discussed the problem of sub synchronous resonance and that the interaction between the frequencies in the electrical grid and the frequency of the turbine segments are equal at certain values if we change the value of the series capacitor has been discussed. The first IEEE standard system was used for the purpose of studying the phenomenon of sub synchronous resonance. The system was analyzed by using eigenvalue the purpose of providing an explanation in case of stability and instability in this analysis. We have four unstable frequencies that lead to problems in the system therefore; different controllers are used for the purpose of improving the stability of the system in addition to damping the sub-synchronous resonance oscillation. This is done by using FACTS control. In this research two types of FACTS control are used TCSC and SVC. It can be extended, also using advance control techniques like fuzzy and neural network also robust control for the purpose of finding the best values for parameters of SVC, AVR and TCSC, excitation system to damp the SSR.

\section{REFRENCES}

1. Hossein Ali Mohammadpour, Seyyed Mohammad Hosein Mirhoseini, and Abbas Shoulaie "Comparative study of proportional and TS fuzzy controlled GCSC for SSR mitigation," Power International Conference on Power Engineering, Energy and Electric Drives, Lisbon, Portugal, pp. 564-569, March 2009.

2.Massimo Bongiorno, Jan Svensson, and Lennart Ängquist "On control of static synchronous series compensator for SSR mitigation," IEEE Tranc. Power Electronics, vol. 23, no. 2, pp. 735-743, 2008.

2. Massimo Bongiorno, Lennart Angquist, and Jan Svensson "A novel control strategy for sub synchronous resonance mitigation using SSSC," IEEE Tranc. Power Delivery, vol. 23, no. 2, pp. 1033$1041,2008$.

3. Akbar Lak, Daryoush Nazarpour, and Hasan Ghahramani, "Novel methods with fuzzy logic and ANFIS controller based SVC for damping sub-synchronous resonance and low-frequency power oscillation," 20th Iranian Conference on Electrical Engineering, (ICEE2012), Tehran, Iran, pp. 450-455, May 15-17,2012.

4. Narendra Kumar, Sanjiv Kumar and Vipin Jain "Damping sub synchronous oscillations in power system using shunt and series connected FACTS controllers," International Conference on Power, Control and Embedded System, Allahabad, India, pp. 1-5,2010.

5.Shashidhara Mecha Kotian, and K. N. Shubhanga," Design of a Subsynchronous Damping Controller Using Adynamie Phasor-Based Model of TCSC," Biennial International Conference on Power and Energy System, 2016.

6. Atia Adrees, Graduate Student Member, IEEE, and Jovica V. Milanović, Fellow, IEEE,"Optimal Compensation of Transmission Lines Based on Minimisation of the Risk of Subsynchronous Resonance", IEEE Transaction on Power System,Digital Object Identifier 10.1109/TPWRS.2422775,( 2015).

7. Anderson, P. M, Agrwal, B.L., Van Ness J.E, "Sub synchronous Resonance in Power. System", IEEE Press New York.1990.

8. Pillai GN, Joyce D,"SSR analysis with a new analytic model of thyristor controlled series capacitor. In: 15th PSCC, 2005.

9. Luiz A. S. Pilotto, Willis F. Long, and Abdel-Aty Edris, Impact of TCSC Control Methodologies on Sub Synchronous Oscillations," IEEE Transaction On Power Deliver,Vol,18,No.1,2003.

10. Meikandasivam S, Nema RK, Jain SK. Behavi oral," study of TCSC device AMATLAB/Simulink implementation". In: Proceedings of world academe of science, engineering and technology, vol. 35; ISSN 2070-3740., 2008.

11. IEEE SSR Task Force, "First benchmark model for computer simulation of sub synchronous resonance "'IEEE Trans. Power Apparatus, Syst. vol PAS-96, pp.1565-1572, Sept /Oct, 1997. 


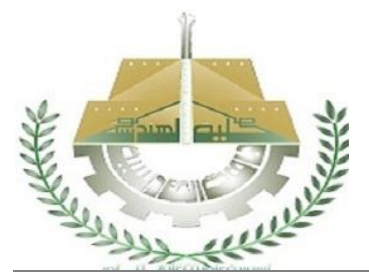

12. S. Tesnjak, G. Erceg, R. Erceg, D.Klarin Z. Komericki,, "Excitation System of thermal Synchronous Turbo Generator," in Power Plant features in the Meaning of Electric Power System Demands, HEP d. d., Zagreb.2000.

13. D. Sumina, G. Erceg, T. Idzotic, "Excitation control of a synchronous generator using fuzzy logic stabilizing controller, 2005.

14. R.Preece, Improving the Stability of Meshed Power Network, spring international publishing switzerland, DOI: 10.1007/978-02393-9-2,(2013).

15. Q. H. Wu and B.W. Hogg, "Robust self-tuning Regulation for a Synchronous Generator", IEEE Proc. ,pt. D, vol. 135,no. 6, pp. 463-473, 1998.

16. R. J. Piwko, C. A. Wegner, S. J. Kinney, and J. D Eden, "Sub synchronous resonance Tr- performance tests of ans. Power Delivery, vol. 11, pp. 1112-1119, Apr. 1996.

17. Majdi M. Alomari,and Jian Guo Zhu," Bifurcation control of subsynchronous resonance using TCSC," Commun Nonl inear Sci Numer Simulat 16 (2011) 2363-2370.

18. A.E. Hammad, M. El Sadek, "Application of a thyristor controlled VAR compensator for damping oscillation of sub synchronous oscillation in power system" IEEE Trans., PAS, vol. 103, no. 1 pp. 198212,1984 .

19. R. J. Piwko, C. A. Wegner, S. J. Kinney, and J. D. Eden," Sub synchronous resonance performance tests of the Slatt thyristor-controlled series capacitor, II IEEE Trans. Power Delivery, vol. 11,pp.1112-1119,1996 